\title{
$\mathrm{RMCP}$ 기반의 응용 계충 멀티캐스트에서 QoS를 고려한 멀티캐스트 트리 구성 기법 \\ 박 시 용 + 김 성 민 ${ }^{++} \cdot$ 정 기 동 $^{++}$
}

요 약

응용 계층 멀티캐스트 프로토콜인 PMCP는 2003년 12월에 ITU-T와 ISO의 멀티캐스트 통신 분과 합동 국제 표준 회의에서 표준 안으로 결 정되었으며.표준에서는 멀티캐스트 트리를 정적으로 구성하는 방식을 제안하였다. 본 논문에서 제안하는 기법은 기존의 RMCP 표준에서 제안 하는 Static Tree 방식보다 초기 지연 시간 및 사용자 요구 QoS측면에서 더 나은 성능을 보이며 동적으로 멀티캐스트 트리를 구성할 수 있는 새로운 QoS 기반 트러 기법을 제안한다. 본 논문에서 제안하는 QoS 기반 트리 기법은 사용자 요구 QoS를 만족할 수 있는 복수 개의 서브넷 그룹을 이용하는 Best-Fit 방법과 최대 전송 대역폭을 가지는 서브넷 그룹을 이용하는 First-Fit 방법으로 구성된다. 본 논문에서 제안하는 두 가지 방법은 기존의 Static 방법보다 우수한 성능을 보였다.

키워드 : QoS, RMCP, 응용 계층 멀티캐스트

\section{Multicast Tree Construction Scheme considering QoS on the Application Layer Multicast based on RMCP}

\author{
Si-Yong Park ${ }^{\dagger} \cdot$ Sung-Min $\mathrm{Kim}^{++} \cdot \mathrm{Ki}-$ Dong Chung $^{\text {t+t }}$
}

\begin{abstract}
RMCP is an application layer multicast protocol and was established as a standand by ITU-T. Also, RMCP includes a scheme which can statically construct a multicast tree.

In this paper, we propose a QoS based tree construction scheme which can dynamically construct a multicast tree. And, this scheme shows more superior performance than the static tree scheme of RMCP in terms of start-up delay and user requirement QoS. This scheme consists of a best-fit method using multiple sub-net groups which are satisfied a user requirement QoS and a first-fit method using one sub-net group which has maximum transmission bandwidth. In simulation result, two proposed methods are superior to the existing static tree scheme.
\end{abstract}

Key Words: QoS, RMCP, Application Layer Multicast

\section{1. 서 론}

멀티캐스트 서비스는 그룹 통신에서 다수의 사용자들에게 동일한 데이터를 전송함으로 발생하는 트래픽을 감소시키기 위해서 중복되는 데이터를 멀티캐스트 라우터를 이용하여 전 송하는 방식이다. 그러나 현재 멀티캐스트 서비스는 수익 모 델 부재와 멀티캐스트 라우터의 불안정성, 트래픽 제어의 불 안정성 등의 문제점으로 인하여 효율적인 서비스의 제공을

※ 본 연구는 정보통신부 정보통신연구진흥원에서 지원하고 있는 정보통신 기 초기술연구지원 사업번호 B1220-0501-0234의 연구결과입니다.

+ 준 회 원 : 부산대학교 전자계산학과 박사

+ 준 회 원: 부산대학교 컴퓨터공학과 박사과정

tt 준 회 원: 부산대한교 컴퓨터공학과 박사고정
+4 종선회원 : 부산대학교 전자계산학과 교수

논문접수 : 2005 년 4월 6일, 심사완료 : 2005 년 9월 21일
어렵게 만들고, 인터넷 라우터들을 멀터캐스트 라우터로 교체 하는데 필요한 비용의 문제도 큰 부담으로 작용한다. 그러나 이러한 멀티캐스트 방식을 사용하지 않을 경우에 많은 수신 자들에게 유니캐스트를 이용하여 덜티미디어 데이터를 전송 해야 함으로 송신자의 접속망 게이트웨이에 많은 연결이 집 중되어 혼잡이 발생한다. 그리고 동일한 데이터를 여러 수신 노드들에게 전송함으로 인해서 중복 패킷에 의한 네트워크 트래픽도 발생한다. 이러한 문제점들을 해결하기 위해서 응용 계층 멀티캐스트(Application Layer Multicast) 전송 방식이 제안되었으며, 이 방식에서는 멀티캐스트 라우터에서 처리하 는 데이터 복사, 경로 배정과 같은 기능을 참여 노드의 애플 리케이션 계층에서 처리한다.

본 논문에서는 데이터의 송, 수신을 담당하는 Data Plane 
과 세션내 멤버 구성, $\mathrm{QoS}$ 를 모니터링하는 Control Plane을 분리하여 독립적으로 데이터 스트림 및 제어 메시지를 운영 할 수 있는 토폴로지를 구성하는 RMCP(Relayed Multicast Control Protocol) 프로토콜을 이용하여 대규모의 네트웍에서 효율적으로 멀티캐스트 서비스를 제공하기 위한 기법들을 제 안한다.

$\mathrm{RMCP}$ 기법은 2002년 8월에 ITU-T SG17 X.rmcp 공식 작업 문서로 등재된 프로토콜이며, 2003년 12월에 ITU-T와 $\mathrm{ISO}$ 의 멀티캐스트 통신 분과 합동 국제 표준 회의에서 표준 안으로 결정되었으며, 표준에서는 정적으로 멀티캐스트 트리 를 구성하는 Static Tree 방식만을 명세하고 있지만 몇 가지 문제점들을 내포하고 있다.[1, 2]. Static Tree 방식은 멀티캐 스트 그룹에 참가하려는 노드에 대한 부모 노드를 SM(Session Manager)에서 하나만을 지정하여 응답하므로 위치상 거리에 따른 지연을 발생시키며, 멀티캐스트 그룹에 진입하는 모든 노드에 관한 정보를 $\mathrm{SM}$ 에서 관리하므로, 과중한 부하가 발생 할 수 있다. 본 논문에서는 이러한 문제점들을 해결하기위해 서 동적으로 멀티캐스트 트리를 구성하는 새로운 QoS 기반 트리 방식을 제안하고, 멀티캐스트 그룹 가입 및 탈퇴 절차 와, 트리 구성 방법 그리고 테이블 구성 방법 등을 소개한다.

현재 멀티캐스트 서비스는 사용자의 요구에 의해서 멀티캐 스트 서비스를 제공받지만, 단말의 환경 및 $\mathrm{QOS}$ 를 전혀 고려 하지 않는다. 최근에 많이 언급되고 있는 유비쿼터스 컴퓨팅 환경에서는 기존의 PC 단말 외에도 경량화 된 임베디드 단말 들이 주를 이룰 것이다. 이러한 환경에서 $\mathrm{PC}$ 단말과 임베디 드 단말이 동일한 멀티미디어 그룹에 속한다면 서로 다른 컴 퓨팅 능력과 $\mathrm{H} / \mathrm{W}$ 에 때문에 동일한 수준의 멀티미디어 데이 터를 수신하기가 어렵다. 본 논문에서는 이를 해결하기 위해 서 단말의 요구 $\mathrm{QOS}$ 를 만족시키는 기법들을 제안한다.

본 논문의 구성은 다음과 같다. 2 장에서는 $\mathrm{RMCP}$ 및 응용 계층 멀티캐스트에 관한 관련 연구에 대하여 살펴보고 3장에 서는 본 논문에서 제안하는 $\mathrm{QOS}$ 를 고려하는 트리 구성 기법 에 대하여 소개한다. 4 장에는 실험 환경과 결과를 분석하고 5 장에서 결론 및 향후 연구 과제를 설명한다.

\section{2. 관련 연구}

본 장에서는 기존의 응용 계층 멀티캐스트의 연구들에 대 하여 살펴본다. 응용 계층 멀티캐스트 그룹은 노드들 간의 연 결 방식에 따라 크게 트리, 메쉬 연결 방식으로 나눈다. 트리 방식에는 TBCP[5], TAG[6], Peercast[7], Host Multicast[8], Overcast[11], YOD[13] 방식이 있으며, 메쉬 연결 방식에는 Narada[3], ALMI[4], Scattercast[12] 방식이 있다. 그리고 트 리와 메쉬 방식이 아닌 기타 방식으로는 중간 노드들을 연결 하는 NICE[10], CAN[9] 방식이 있다.

트리 방식의 대표적인 YOID 기법은 'Your Own Internet Distribution(YOD)' 프로젝트에서 제안된 방식으로 특정 그 륩에 참여하는 수신 호스트 간에 논리적 트리를 구성하며 트 리를 따라서 각 호스트 간에 유니캐스트 중계를 시도한다. 응
용 계층 멀티캐스트 관련 기술 개발 중에 가장 왕성한 활동 을 보이고 있으며, 다수의 송신자를 지원하는 메쉬 토폴로지 를 유지하면서 동시에 자동으로 구성되는 터널로 연결된 공 유 트리를 기반으로 한다[13]. PeerCast는 peer들간의 스트림 을 포워덩하는 트리 기반의 오버레이 네트워크이다. 이것은 중간 정도의 유연성을 가지고 동적으로 변하는 그룹을 위해 설계되었다. PeerCast는 상위 응용 계층과 아래 전송 계층 사 이에 Peering Layer를 두고 이 Peering Layer에서 데이터 전 달을 위한 세션을 형성한다[7].

메쉬 연결 방식의 대표적인 응용 계층 멀티캐스트 기법은 Scattercast이다. Scattercast는 scattercast proxies(SCXs)를 이용해서 큰 규모의 멀티캐스트와 여러 응용 프로그램 요구 에 잘 적응할 수 있는 효율적인 인프라 스트럭쳐 구축을 가 능하게 한다. Scattercast기법은 이질적인 특성을 가진 네트워 크들 간에 Overlay 접근을 시도하며, 지능적인 대리인인 $\mathrm{SCXs}$ 를 이용하는 특징이 있다[12]. Scattercaster는 응용 계 층에서의 직접적인 특정 응용 프로그램 서비스 모듈을 사용 하는 대리인을 사용하여 호율적인 혼잡 제어, 신뢰성, 대역폭 할당 등의 문제들을 해결하였으나 비용이 증가하는 문제가 있다. 라우터를 이용하지 않고 종단의 SCXs들이 데이터의 흐 름을 관장하기 때문에 불가피하게 추가적인 지연이 일어난다. 또한 라우팅, 포워딩 알고리즘이 라우터가 아닌 소프트웨어 상에서 실행되기 때문에 SCXs들이 충분한 데이터 처리랑을 유지할 수 없는 단점이 있다[12].

ALMI(Application Level Multicast Infrastructure)는 다대 다 통신을 하는 상대적으로 작은 그룹 멤버들이 넓은 지역에 산재해 있는 멀티캐스트 그룹에게 신뢰성 있는 서비스를 제 공하기 위하여 플러그인 구조로 개발되었다. ALMI는 멀티 캐스트 방식을 이용하는 응옹 프로그램을 위한 미들웨어로서 멤버 수가 적은 그룹에 대해 유연한 다대다 멀티캐스트를 제 공한다[4].

이러한 기존의 응용 계층 멀티캐스트 기법들은 기존의 IP 멀티캐스트와는 달리 모든 peer들이 중간 노드의 역할을 대 신 수행하기 때문에 멀티캐스트 노드들 간의 연결 방식 및 전체 구조에 중점을 두었고, 전송 노드들의 대역폭 및 노드들 의 계산 능력과 같은 $\mathrm{QOS}$ 인자를 전혀 고려하지 않았다. 이 에 본 논문에서는 사용자의 요구 $\mathrm{QoS}$ 를 고려하는 멀티캐스 트 트리 구성 기법을 제안한다.

$\mathrm{RMCP}$ 는 다른 응용 계층 멀터캐스트 기법들과는 달리 Data Plane과 Control Plane이 구분된다. 그러므로, 기존의 미디어 전송 프로그램, 즉, 윈도우 미디어 플레이어, 리얼 쯜레이어와 같은 프로그램을 이용하여 미디어 전송을 담당하고, 별도의 제어 모듈을 이용하여 멀티캐스트 서비스를 제공한다. RMCP 는 범용적인 오버레이 멀티캐스트 네트위크를 구성하기 위한 방법이며 서비스 토폴로지는 송수신 응용과 IP 멀티캐스트 라우터의 전송기능을 담당하는 MA(Multicast Agent)와 그룹 멤버쉽 관리와 통신 상태 감시를 하기 위한 $\mathrm{SM}$ (Session Manager)으로 구성된다. $\mathrm{MA}$ 와 $\mathrm{SM}$ 은 송수신자 호스트와는 별도의 서비스를 통해 구현한다. RMCP는 전형적인 오버레이 
멀티캐스트 전송 서비스 이외에도 그룹마다 별도의 특성을 부여하여 통신 중 그륩 상태의 감시 기능 둥을 제공하며, 고 정된 망 장비가 아닌 동적인 종단 $\mathrm{PC}$ 를 사용하기 때문에 빈 번히 발생할 수 있는 데이터 전송 경로의 변경이나 오류에 강건한 메커니즘을 제공한다. 아울러 표준화된 범용 사용자 인터페이스를 제공한다[1]. RMCP 표준에서는 세션 가입 절 차에 대해서 Static, Automatic Tree 방식을 제공한다. SM이 새로운 노드에 하나의 부모 노드를 지정하는 것을 Static Tree 방식이라고 하고, 새로운 노드에 대하여 선택적인 여러 후보 부모 노드를 지정하는 것을 Automatic Tree방식이라 한다. RMCP 표준에서는 Static Tree 방식만을 정의하고 있 으며, Automatic Tree방식에 대해서는 차후 과제로 제시하고 있다[2].

(그림 1)에서는 RMCP의 기본 전송 과정 및 Control Plane 과 Data Plane을 보인다. Multimedia 전송을 위해서 SMA (Sender Multicast Agent)가 서비스를 제공하고, 중간 노드인 $\mathrm{MA}$ (Multicast Agent)가 중계 역할을 담당하여 미디어 데이 터를 전달한다. 이러한 구성을 이용하여 덜티미디어 데이터를 미디어 응용 프로그램이 연결되어 있는 MA까지 전달한다.

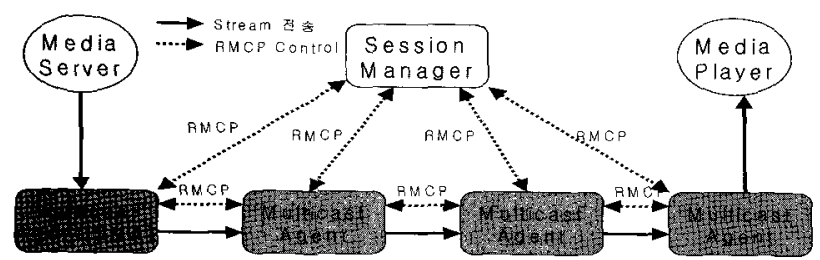

(그림 1) RMCP 기반의 스트리밍 전송

$\mathrm{RMCP}$ 에서는 <표 1>과 같은 제어 메시지를 사용하며, 각 메시지는 크게 3 개의 쌍으로 이루어져 있다. 각 쌍의 메시지 는 요구, 확인을 위한 메시지로 이용한다. JR, JC 메시지는 세션 가입을 위한 메시지이며, $\mathrm{RR}, \mathrm{RC}$ 메시지는 부모, 자식 노드간의 연결을 시도할 때 사용하는 메시지이다. SR, SC 메 시지는 세션 관리자가 세션에 참가하고 있는 노드들의 정보 를 유지, 관리하기 위해서 주기적으로 교환하는 메시지이다.

〈표 1) RMCP 메시지

\begin{tabular}{|c|c|c|c|}
\hline Message & RMCP Operation & From & To \\
\hline Join Request(JR) & \multirow{2}{*}{ Session Join } & MA & Session Manager \\
\cline { 4 - 4 } Join Confirm(JC) & & Session Manager & MÁ \\
\hline Relay Request(RR) & \multirow{2}{*}{ Data Channel Control ol } & DownStream MA & UpStream MA \\
\cline { 3 - 4 } & & UpStream MA & Down Sontream MA \\
\hline Status Report(SR) & \multirow{2}{*}{ Session Monitoring } & MA & Session Manager \\
\cline { 3 - 4 } & & Sescion Manager & MA \\
\hline
\end{tabular}

\section{3. 응용 계층 멀티캐스트에서 QoS를 고려한 트리 구성}

본 장에서는 응용 계층 멀티캐스트에서 QOS를 고려한 트 리 구성 기법에 대하여 설명한다. 표준으로 정의된 $\mathrm{RMCP}$ 기
법은 Static Tree 방식을 이용한 멀티캐스트 서비스를 제공한 다. 이 방식은 $\mathrm{SM}$ 이 멀티캐스트 그룹 내의 모든 노드에 대한 정보를 유지하고 관리하기 때문에 많은 노드들을 관리할 경 우에는 SM에 부하가 발생할 수 있으며, 새로운 노드를 위하 여 부모 노드를 하나만 지정함으로서 거리에 따른 전송 지연 이 발생하고 또한 노드들의 요구 대역폭을 충분히 활용하지 못하는 단점이 있다. 이러한 문제점을 개선하기 위해 본 논문 에서는 QOS 기반 트리 방직을 제안하고 그에 따른 Tree ID 설정, Table 정보 관리 및 멀티캐스트 그룹의 가입 및 탈퇴 절차를 설명한다.

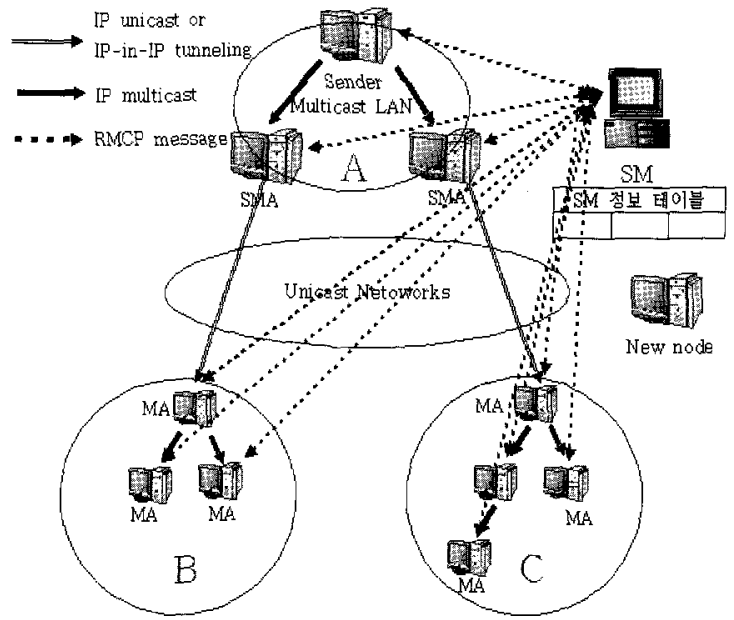

(그림 2) Static Tree 방식를 이용한 RMCP 서비스

(그림 2)에서는 Static Tree 방식을 이용한 RMCP의 멀티 캐스트 서비스 방식을 보인다. (그림 2)에서 서브넷 그룹 $\mathrm{A}$ 에 송신자와 SMA(Session Manager Agent)가 위치하고, 서브넷 그룹B와 $\mathrm{C}$ 에는 중계 역할을 하는 $\mathrm{MA}($ Multicast Agent)와 수신자가 존재한다. 그리고 $\mathrm{SM}$ 은 어느 곳에든지 존재할 수 있으며, 모든 MA 및 SMA에 대한 정보를 유지하고 멀티캐 스트 트리를 유지 관리한다. 그리고 Static Tree 방식을 이용 하여 멀티캐스트 그룹을 형성 할 때는 아래의 과정을 따른다.

먼저, 새로 멀티캐스트 그룹에 참가하려는 노드가 JR(Join Request)메시지를 이용하여 SM에게 진입을 요청하면, 새 노 드가 $\mathrm{A}, \mathrm{B}, \mathrm{C}$ 의 어느 서브넷 그룹안에 위치하는지를 조사한 다. 만일 새 노드가 $\mathrm{A}, \mathrm{B}, \mathrm{C}$ 서브넷 그룹중 어느 하나에 위 치하고 있다면 해당 서브넷 그룹에서 부모 노드를 검색한다. 그러나 새 노드가 $\mathrm{A}, \mathrm{B}, \mathrm{C}$ 서브넷 그룹중에 어느 곳에도 위 치하지 않는다면, 독립적인 서브넷 그룹을 형성한다. 그리고 멀티캐스트 트리의 깊이가 가장 작은 서브넷 그륩을 부모 서 브넷 그룹으로 지정하고, 부모 서브넷 그룹 중 하나의 노드를 부모 서브넷 그룹으로 지정한다. 부모 서브넷 그륩에서 부모 노드를 선택하는 조건은 먼저 자식 노드를 허용하는지 조사 하고, 현재 부모 노드에 연결되어 있는 자식 노드의 수와 서 브넷 그룹의 Tree Level을 검사하여 적절한 부모 노드를 선 택한다.

Static Tree 방식은 멀티캐스트 망에 새롭게 서비스를 요 
청하는 노드에 대하여 부모 노드 하나만을 지정하는 방식이 기 때문에 거리에 따른 전송 지연이 발생한다. 예를 들어, 새 로 서비스를 요구하는 노드가 $\mathrm{C}$ 서브넷 그룹 근처에 있다고 가정하면 $\mathrm{SM}$ 에서는 $\mathrm{B}$ 서브넷 그룹의 Tree Level이 짧기 때 문에 $\mathrm{B}$ 서브넷 그룹의 노드 중 하나의 노드를 부모 노드로 지정한다. 그러나 새로 서비스를 요청하는 노드가 $\mathrm{C}$ 서브넷 그룹에서 데이터를 전송 받는다면 더 빠른 송신이 가능하다. 이와 같이, 서브넷 그룹의 Tree Level을 기준으로 부모 노드 를 지정한다면 전송 지연이 발생 할 수 있다. 그리고 하나의 $\mathrm{SM}$ 서버가 모든 MA와 연결하여 제어 메시지를 송수신하는 중앙 집중형 방식을 이용하기 때문에 모든 MA들의 제어 메 시지로 인하여 많은 부하가 발생할 수 있다.

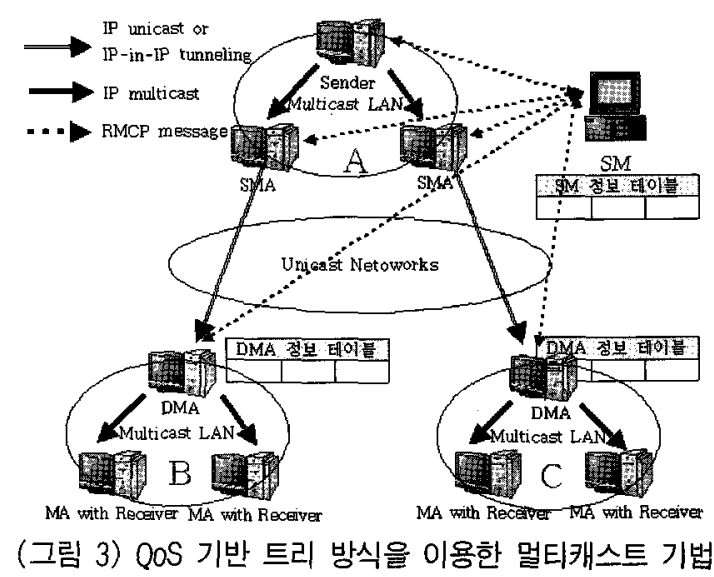

(그림 3)에서는 $\mathrm{QoS}$ 기반 트리 방식을 이용한 멀티캐스트 기법을 설명한다. QoS 기반 트리방식의 멀티캐스트 서비스는 $\mathrm{QoS}$ 를 고려한 확장성, 결함 허용, 신뢰성을 고려하기 때문에 $\mathrm{SM}$ 은 전체 멀티캐스트 트리의 대표 정보를 관리하고, DMA 는 서브넷 그룹의 가장 상위 노드로서 각각의 서브넷 그룹의 멀티캐스트 트리 정보를 유지 관리한다.

\subsection{Tree ID 설정}

본 논문에서는 노드의 식별성을 높이고, 트리 재구성을 쉽 게 하기 위해서 새롭게 Tree $\mathrm{ID}$ 를 설정하는 방법을 설명한 다. 그리고 이러한 Tree $\mathrm{ID}$ 는 서브넷 그룹의 분할 및 노드들 의 참여와 탈퇴에서 노드들의 트리내 위치 인식을 위해서 사 용한다. (그림 4)는 하나의 서브넷 그룹에서의 트리 구성을 나타낸다.

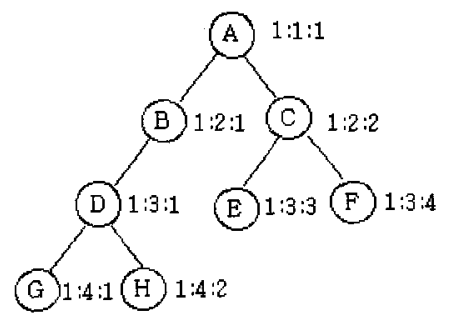

(그림 4) Tree 10 구성
(그림 4)에서는 2진 트리에서 Tree $\mathbb{D D}$ 를 부여하는 방법을 설명한다. Tree $\mathrm{ID}$ 는 Subnet Number, Level Number, Node Number로 구성되며 Subnet Number는 고유한 Subnet을 나 타내는 양의 정수 값이고 Level Number는 트리의 Level을 나타내며, Node Number는 노드의 번호를 나타낸다. Node Number는 (식 1)의 조건을 적용하여 설정한다.

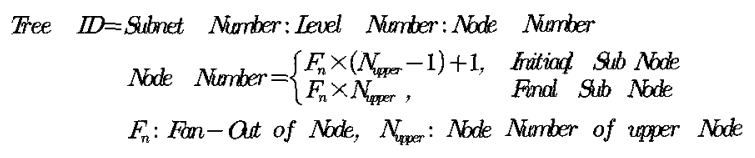

(식 1)에서 Initial Sub Node는 첫 번째 자식 노드의 Tree ID 부여 방법이고 Final Sub Node는 두 번째 자식 노드의 Tree $\mathrm{ID}$ 를 계산하는 방법이다. 예를 들어, $\mathrm{E}$ 노드의 경우 Subnet Number가 1, Level Number가 3이고, 첫 번째 노드 이기 때문에 Initial Sub Node의 수식에 의해서 $F_{n}$ 은 2 이고 $N_{\text {upper }}$ 도 2이므로 (식 1)에 의해서 Node Number는 3이다. F 노드는 2번째 노드이므로 Final Sub Node의 방식에 따른다. 위와 같은 방법을 이용하면 $\mathrm{C}$ 노드의 첫 번째 자식 노드는 1 : $3: 3$ 의 Tree $\mathbb{D}$ 를 부여받는다. $F_{n}$ 은 트리 구성상의 Fan-out 이며 한 노드가 가질 수 있는 자식 노드의 개수를 나타낸다. $N_{\text {upper }}$ 는 부모 노드의 Node Number를 나타낸다.

\subsection{Table 정보 관리}

(그림 5)에서는 QoS 기반 트리 방식을 이용하여 멀티캐스 트 서비스를 제공하는 망 구조를 설명한다. 망 분산화는 표준 $\mathrm{RMCP}$ 에서 이용하는 방식과 같이 서브넷 그릅 단위로 이루 어진다. (그림 5)에서 점선은 제어 메시지를 위한 경로를 나 타내며, 실선은 데이터를 전송하는 경로를 나타낸다.

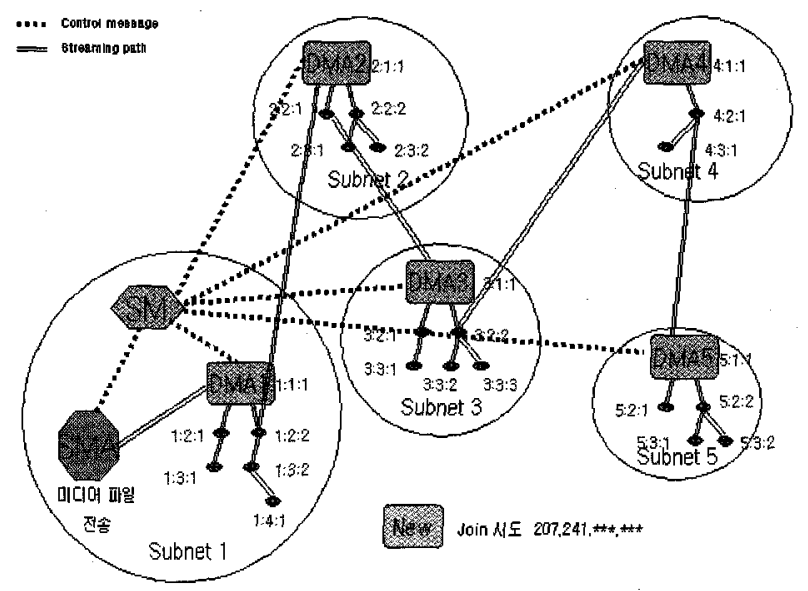

(그림 5) RMCP기반의 Automatic Tree 방식

QoS 기반 트리 방식을 이용하는 멀티캐스트 서비스는 QoS를 고려한 확장성, 결함 허용, 신뢰성을 관리하기 위해 $\mathrm{SM}$ 과 $\mathrm{DMA}$ (Designated $\mathrm{MA}$ : 서브넷 그룹에서 가장 상위 노. 
드)에 각각 <표 2>, <표 3>과 같은 정보 테이블의 정보들이 필요하다.

〈표 2〉SM의 정보 테이블

\begin{tabular}{|c|c|c|c|c|c|c|c|}
\hline From & To & Gate & $\begin{array}{c}\text { Tree } \\
\text { ID }\end{array}$ & Dest & Subt & $\begin{array}{l}\text { Aver } \\
B / W\end{array}$ & $P_{\text {Dect }}$ \\
\hline SMA & $A 1$ & 164.125 .164 .1 & $1: 1: 1$ & 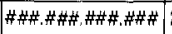 & 255.255 .252 .0 & $325 \mathrm{~kb} / \mathrm{s}$ & $1: 2: 1$ \\
\hline MA1 & MA2 & $* * * * * * * *$ & $2: 1: 1$ & \#\#\#,\#\#\#: & $255,255,192,0$ & $294 \mathrm{~kb} / \mathrm{s}$ & $2: 2: 1$ \\
\hline MA2 & DMA3 & $* * *, * * * * * * * *, * * *$ & $3: 1: 1$ & 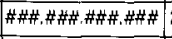 & $255.255 .255,0$ & $265 \mathrm{~kb} / \mathrm{s}$ & $3: 2: 2$ \\
\hline MA3 & DMA4 & $* * *, * * * *, * * *, * * *$ & $4: 1: 1$ & 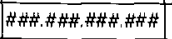 & 255.255 .0 .0 & $243 \mathrm{~kb} / \mathrm{s}$ & $4: 2: 1$ \\
\hline
\end{tabular}

<표 2>의 From 필드는 데이터의 송신 노드를 나타내며, To 필드는 미디어의 수신 노드를 나타낸다. Gateway 정보 필드는 서브넷 그룹의 게이트웨이 정보를 나타내고, Tree $\mathrm{ID}$ 는 노드의 식별 $\mathrm{ID}$ 를 나타낸다. Gateway의 정보는 RMCP 표 준에서 정의한 세션 관리를 위한 SR(Status Report) 메시지 에 첨가하여 각 $\mathrm{DMA}$ 가 $\mathrm{SM}$ 에게 전달한다. IP Address와 Subnetmask 필드는 각각 수신 노드의 주소 정보와 고유한 서브넷 그룹을 표현하기 위한 Subnet Mask 정보를 기록한 다. Aver $\mathrm{B} / \mathrm{W}$ 필드는 각 서브넷 그릅에서 사용하는 평균 대 역폭을 나타내고, (식 2)를 이용하여 구한다. Best node는 해 당 서브넷 그룹내의 자식 노드를 수용할 여유가 있는 노드들 중에서 가장 전송 대역폭이 큰 노드를 표시하고, 신규 노드가 가입을 위해서 선택된 서브넷 그룹의 첫 번째 부모노드로 선 택된다.

$$
\text { Average } B / W=\sum_{i=1}^{n} l_{b / u}^{i} / N
$$

$l_{b, w}^{i}$ : 서브넷 그룹 내의 링크 $i$ 의 대역폭

$N$ :서브넷 그룹 내의 링크 수

(식 2)의 Average $B / W$ 는 새로운 노드가 멀티캐스트 서비 스에 참여할 때 적절한 서브넷 그룹을 검색하기 위해서 사용 한다.

〈표 3〉 DMA의 정보테이블

\begin{tabular}{|c|c|c|c|c|c|c|}
\hline Tree ID & From & To & Gateway & $\mathbb{P}$ addr & Subnetmask & FromTo B/W \\
\hline $1: 2: 1$ & $1: 1: 1$ & $1: 2: 1$ & 164.125 .164 .1 & 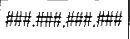 & 255.255 .252 .0 & $473 \mathrm{~kb} / \mathrm{s}$ \\
\hline $1: 2: 2$ & $1: 1: 1$ & $1: 2: 2$ & $* * *, * * * * * * * * * * *$ & 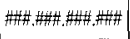 & 255.255 .252 .0 & $323 \mathrm{~kb} / \mathrm{s}$ \\
\hline $1: 3: 1$ & $1: 2: 1$ & $1: 3: 1$ & $* * *, * * * * * * *, * * *$ & 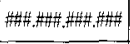 & 255.255 .252 .0 & $313 \mathrm{~kb} / \mathrm{s}$ \\
\hline $1: 3: 2$ & $1: 2: 2$ & $1: 3: 2$ & $* * * * * * * * * * * * * *$ & 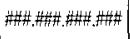 & 255.255 .252 .0 & $264 \mathrm{~kb} / \mathrm{s}$ \\
\hline $1: 4: 1$ & $1: 3: 2$ & $1: 4: 1$ & $* * * * * * * * * * * * * * *$ & 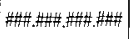 & 255.255 .252 .0 & $253 \mathrm{~kb} / \mathrm{s}$ \\
\hline
\end{tabular}

<표 3>은 각 서브넷 그륩의 최상위 노드에서 유지 관리하 는 테이블이다. FromTo B/W 필드는 From 필드의 노드와 To 필드의 노드사이의 link 전송 속도를 나타내며 $\mathrm{SM}$ 과 $\mathrm{DMA}$ 정보 테이블들은 $\mathrm{RMCP}$ 의 제어 메시지 중 $\mathrm{SR}, \mathrm{SC}$ 정 보에 의해서 주기적으로 정보 교환이 이루어져 지속적으로 데이터를 갱신한다.

QOS 기반 트리 방식에서 각각의 서브넷 그룹 멀티캐스트 Tree의 노드가 증가하면서 노드들의 그릅 참여와 탈퇴가 빈
번하게 발생하여 서브넷 그릅 내부의 전송 대역폭의 차를 크 게 만들고, 전송 대역폭의 차가 커지면 뎀버들의 QoS는 보장 되기 힙들다. 결국 멤버들의 QoS요구를 만족시키기 위해서 하나의 서브넷 그룹을 두개의 서브넷 그룹으로 분할해야한다. 그리고 서브넷 그룹 분할의 조건은 (식 3)과 같다.

$$
B_{M a x}^{a}-B_{M i n}^{a}>\beta_{b a n d w i d t h}
$$

(식 3)에서 $B_{M a x}^{a}$ 는 서브넷 그룹 $a$ 의 링크들 중 최대 전송 대역폭이고 $B_{\mathrm{Mnn}}^{a}$ 서브넷 그룹 $a$ 의 링크들 중 최소 전송 대역 폭이다. (식 3)와 같이 서브넷 그룹 내의 최대 대역폭과 최소 대역폭의 차이가 임계치 $\beta_{b a n d w i d t h}$ 보다 크다면 (식 4)를 기준 으로 하여 두 개의 서브넷 그룹으로 분할한다. 두 개의 서브 넷 그룹으로 분할하기 위해서 (식 4)보다 더 큰 전송 대역폭 을 가지는 노드들을 하나의 서브넷 그룹으로 묶고, 더 낮은 전송 대역폭을 가지는 노드들을 하나의 그룹으로 묶어서 두 개의 서브넷 그룹으로 분할한다.

$$
\frac{B_{M a x}^{a}-B_{M i n}^{a}}{2}
$$

그러고 분할된 각각의 서브넷 그룹은 전송 대역폭이 가장 큰 노드를 최상위 노드(DMA)로 정하고 전송 대역폭 크기순 으로 서브넷 그룹의 트리를 재구성한다.

각각의 서브 넷 그룹에서 그룹 참여와 탈퇴가 빈번하게 발 생하여 하나의 서브넷 그룹이 너무 작은 노드를 포함하면 위 의 알고리즘과 반대되는 방법으로 두개의 서브넷 그룹을 병 합한다.

\section{3 세션 가입 및 탈퇴}

멀티캐스트 서비스에서 미디어 스트림 서비스를 이용하기 위해서는 먼저 멀티캐스트 그룹의 멤버로 가입을 하여야 한 다. 본 절에서는 새로운 노드가 멀티캐스트 그룹에 가입 및 달퇴하는 절차에 대하여 설명한다. QOS 기반 트리 기법에서 멀티캐스트 그륩의 가입 절차는 두 가지 방법이 있다. 새로운 노드가 멀티캐스트 그룹에 가입을 시도할 때, 어느 서브넷 그 룹에 연결할 것인지를 결정하고, 서브넷 그룹내에서 어느 노 드에 연결할 것인지를 결정하여야 한다. 새로운 노드가 참여 할 서브넷 그룹과 부모 노드를 검색하기 위해서 Intra connection 방법과 Inter connection 방법을 사용한다. 신규 노드 가 멀터캐스트 그룹에 참여할 때 신규 노드가 참여 할 서브 넷 그룹을 찾는 방법을 Intra connection이라 하고, 신규 노드 가 참여할 서브넷 그룹을 찾은 후에 해당 서브넷 그룹에서 부모 노드를 찾는 방법을 Inter connection 방법이라 한다. 서 브넷 그룹을 찾기 위한 Intra connection 방법에는 First-Fit 과 Best-Fit이 있다.

Intra connection 방법에서는 <표 1>의 메시지를 이용하여 서브닛 그릅 정보를 새 노드에게 제공하는데 본 논문에서는 서브넷 그룹 정보 제공 방법으로 First-Fit 과 Best-Fit을 제 
안한다. First-Fit은 SM 테이블상에서 최대 평균 대역폭 가 지는 서브넷 그룹의 정보를 제공하며, Best-Fit은 수신측이 요구하는 대역폭를 가진 서브넷 그룹의 정보를 제공한다.

〈표 4〉 SM의 정보 (First-Fit 방식)

\begin{tabular}{|c|c|c|c|c|c|c|c|}
\hline From & To: & Gatewa & Tro & Des I Pdo & Subbet mask & BVyer & Bost nod \\
\hline SMA & MA1P & $164,125,164,1$ & 1:1:1 & 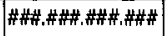 & 255.255 .252 .0 & $325 \mathrm{~kb} / \mathrm{s}$ & $1: 2: 1$ \\
\hline $\mathrm{MA}$ & DMA2, & $* * *, * * * *, * * * *, * * * \mid$ & $2: 1: 1$ & 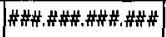 & 255.255 .192 .0 & $294 \mathrm{~kb} / \mathrm{s}$ & $2: 2: 1$ \\
\hline MA2 & DMA3, & $* * 4,4 * 4, * * *+, * * * * 1$ & $3: 1: 1$ & 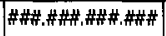 & 255.255 .255 .0 & $265 \mathrm{~kb} / \mathrm{s}$ & $3: 2: 2$ \\
\hline MA3 & DMA4 & $* * *$ & 4:1:1 & 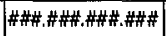 & 255.255 .0 .0 & $243 \mathrm{~kb} / \mathrm{s}$ & $4: 2: 1$ \\
\hline MA4 & DMA5, & s**** & $5: 1: 1$ & F\#\#.\#\#,\#\#,\#\# & 255.255 .128 .0 & $229 \mathrm{~kb} / \mathrm{s}$ & 5:2:1 \\
\hline
\end{tabular}

예를 들어, $\mathrm{SM}$ 이 새로운 JR 메시지를 반았을 경우에 First-Fit을 이용한다면 SM은 테이블을 참조하여 테이블상의 전송 대역폭이 가장 큰 서브넷 그룹의 정보를 포함하여 웅답 하게 된다. 즉, <표 $4>$ 와 같이 상위 3 개의 서브넷 그룹의 $\mathrm{DMA}$ 의 정보를 멀티캐스트 그륩에 참가하려는 노드에게 보 내고 노드는 최대 전송 대역폭을 가지는 서브넷 그룹으로부 터 부모 노드를 검색하기 시작한다.

〈표 5〉 SM의 정보 테이블 (Best-Fit 방식)

\begin{tabular}{|c|c|c|c|c|c|c|c|}
\hline$m$ & To & Gateway & $\begin{array}{l}\text { Tree } \\
\text { iD }\end{array}$ & Dest I add & Subnet mask & $\begin{array}{l}\text { Awer } \\
\mathrm{B} / \mathrm{H}\end{array}$ & Best rode \\
\hline $\mathrm{MA}$ & OMA1 & & $1: 1: 1$ & & 2.0 & $325 \mathrm{k}$ & $1 \cdot 2$ \\
\hline IA1 & DMA2 & $* * * * *$ & $2: 1: 1$ & |\#\#开 & 255.2 & $294 \mathrm{~kb}$ & 2:2:1 5 \\
\hline MA.2 & DMA3 & $* * \infty ;, *+\infty$ & $3: 1: 1$ & 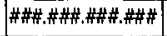 & 255.255 .255 .0 & $265 \mathrm{~kb} / \mathrm{s}$ & $3: 2: 2$ \\
\hline A3 3 & DMAA & $* * * ; * * * ;$ & 4:1:1 & 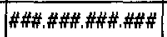 & 255.255 .0 .0 & $243 \mathrm{~kb} / \mathrm{s}$ & $2: 1$ \\
\hline 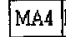 & & & $5: 11$ & 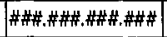 & 255.2 & $29 \mathrm{~kb}$ & $5: 2:$ \\
\hline
\end{tabular}

Best-Fit은 새로운 수신 노드에서 요구하는 대역폭을 가진 서브넷 그룹의 정보를 제공하는 방법이다. 예를 들어 새로 진 입하려는 노드가 $250 \mathrm{~kb} / \mathrm{s}$ 의 대역폭을 요구한다면, <표 $5>$ 와 같이 진입 노드의 전송 요구 속도와 유사한 대역폭을 가진 서브넷 그룹의 정보를 전달하게 된다.

Inter connection 방법에서는 새로 진입할 노드가 선택된 서브넷 그룹에서 부모 노드를 찾기 위해서, 선택된 서브넷 그 룹의 $\mathrm{DMA}$ 에게 가입 요청을 하여 부모 노드를 검색한다. 부 모 노드를 찾기 위한 조건은 먼저 서브넷 그룹내에서 최대의 전송 대역폭을 가진 link에 연결된 자식 노드를 허용하는 노 드들을 검색한다. 만약 검색된 부모 노드가 다수이면 Tree Level의 깊이가 최소인 부모 노드를 찾는다. 예를 들어, $\mathrm{DMA}$ 가 새 노드에게서 진입 요청을 받으면, $\mathrm{DMA}$ 의 정보 테 이블에서 FromTo B/W 필드 기반으로 전송 대역폭이 최고인 노드를 찾은 다음, 그 노드가 자식 노드의 연결을 허용하는지 와 Fan out 범위에 속하는지 조사하고, Tree Level이 최소인 부모 노드를 찾는다. 만일 자식 노드 연결을 허용하지 않는다 면, 다시 그 다음 전송 대역폭을 가진 차기 노드를 찾아서 위 와 같은 방법을 계속 수행한다. 이러한 방식으로 노드들을 구 성한다면 상위 노드의 전송율은 항상 하위 노드의 전송율보 다 클 것이다.

기존의 Static Tree 방식에서는 노드가 탈퇴하기 위해서는
탈퇴 노드가 먼저 $\mathrm{SM}$ 에게 탈퇴 메시지를 전달하고 탈퇴를 한 후에 그 하위 노드들은 트리를 재구성한다. 반면, $\mathrm{QOS}$ 기 반 트리 방식에서는 탈퇴 노드의 주변 노드와 $\mathrm{SM}$ 에게 탈퇴 의사를 전달하고, 탈퇴 노드의 하위 노드들은 하위 트리 구조 에 따라서 이진 트리인 경우에는 두 개의 그룹으로 나누고 각 그륩의 전송율 편차와 Tree의 깊이를 고려하여 탈퇴하는 노드의 하위 멀티캐스트 트리를 재구성한다. 만일 자식 노드 가 하나이면, 하위 그룹을 나눌 필요 없이 탈퇴하는 부모 노 드의 역할을 자식 노드가 대신한다. 트리를 재구성하는 방법 은 하위 멀티캐스트 그룹의 최상위 노드들 중에서 재구성 비 용이 가장 작은 그룹의 최상위 노드가 탈퇴 노드를 대체한다. 그러나 재구성 비용이 낮은 하위 그룹 Tree의 최상위 노드보 다 재구성 비용이 높은 하위 그룹 Tree의 최상위 노드가 더 높은 전송 대역폭을 가지는 경우가 생겨서 전송 대역폭의 계 층성이 역전 될 수 있다. 이런 경우에는 최상위 노드의 전송 대역폭이 높은 하위 그룹 트리의 최상위 노드가 탈퇴 노드를 대신한다.

$$
B_{d e p t h}^{A v g}=\frac{B_{\max }^{G}-B_{\min }^{G}}{T_{\text {depth }}^{G}}
$$

(식 5)는 하위 그룹별 Tree의 깊이당 평균 전송율을 나타 낸다. $B_{\max }^{G}$ 는 하위 그륩의 최대 전송율이고 $B_{\min }^{G}$ 은 하위 그룹 의 최소 전송율이다. 그리고 $T_{d e p t h}^{G}$ 는 하위 그룹 Tree의 깊이 수이다.

$$
C_{\text {Tree }}^{R}=\left|B_{\text {Out }}^{P}-B_{d e p t h}^{A v g}\right|
$$

(식 6)은 하위 그륩별 Tree의 재구성 비용을 나타내고, $B_{\text {Out }}^{P}$ 은 탈퇴 노드의 부모 노드 전송량이다. 만역 하위 그룹 Tree의 재구성 비용 $\left(C_{T r e e}^{R}\right)$ 이 높다는 것은 현재 탈퇴하는 노 드와 하위 그룹의 노드들 간의 대역폭 차가 크다는 것을 의 미한다. 그러므로 탈퇴 노드를 재구성하는 비용이 높은 그룹 의 최상위 노드로 대체한다면 하위 노드의 전송 대역폭 편차 가 커져서 전체적인 $\mathrm{QOS}$ 의 하락을 유발시킨다.

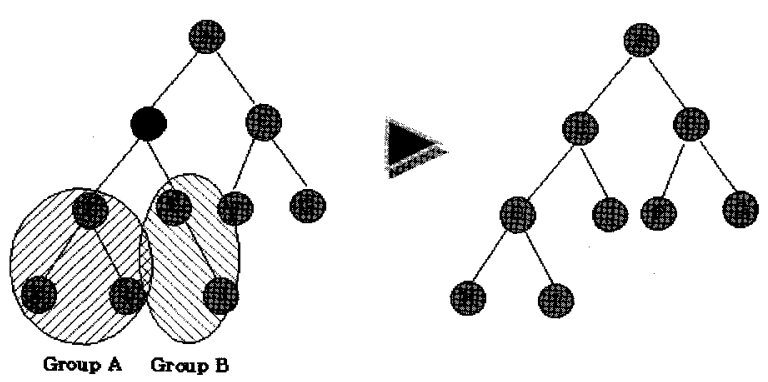

(그림 6) 세션 탈퇴

예를 들어 (그립 6)에서 B노드가 탈퇴하는 과정을 살펴보 면, $\mathrm{B}$ 노드는 $\mathrm{DMA}$ 에게 탈퇴 신청을 하고 $\mathrm{DMA}$ 는 정보 테 
이블을 참조하여 $\mathrm{B}$ 노드 주변노드(부모, 자식 노드)에 대한 정 보를 $\mathrm{B}$ 노드에게 전달한다. 그리고 $\mathrm{B}$ 노드는 $\mathrm{A}, \mathrm{D}, \mathrm{E}$ (부모, 자식 노드)노드에게 leave signal을 보낸 후 $\mathrm{B}$ 노드는 미디어 재생을 멈추고, 스트림의 라우팅 역할을 지속적으로 진행한 다. 그 후에는 B 노드를 기준으로 하위 그룹 Tree의 재구성 비용 $\left(C_{T r e e}^{R}\right)$ 이 작은 그륩의 최상위 노드를 찾는다. (그림 6)에 서 $\mathrm{E}$ 노드 그룹의 재구성 비용 $\left(C_{T r e e}^{R}\right)$ 이 작으므로 $\mathrm{E}$ 노드를 $\mathrm{B}$ 노드의 자리로 대치한다. 그리고 $\mathrm{E}$ 노드는 $\mathrm{D}, \mathrm{H}, \mathrm{I}, \mathrm{J}$ 를 오른 편 그림과 같이 차례로 연결한다. 만약 $\mathrm{E}$ 노드가 (그림 6)과 달리 두개의 하위 그룹을 가지고 있다면 위에서 설명한 알고 리즘에 따라서 다시 하위 그룹을 재구성한다. 그리고 만약 $\mathrm{E}$ 노드가 두 개의 하위 그룹이 아닌 두 개의 자식 노드만 가진 다면 각각의 자식 노드에 따라서 (식 5)의 $B_{\max }^{G}-B_{\min }^{G}$ 대신 하위 노드의 수신랑을 이용하고 $T_{d e p t h}^{G}$ 는 1 로 대입하여 (식 6) 의 재구성 비용을 구한다.

\section{4. 실험 및 성능 평가}

본 장에서는 본 논문에서 제안한 기법들의 성능을 기존의 $\mathrm{RMCP}$ 표준에서 제안한 Static Tree 방식과 비교 분석한다. 제안한 기법들의 실험을 위해서 (그림 7)과 같은 Transit Stub 토폴로지 망을 이용한다.

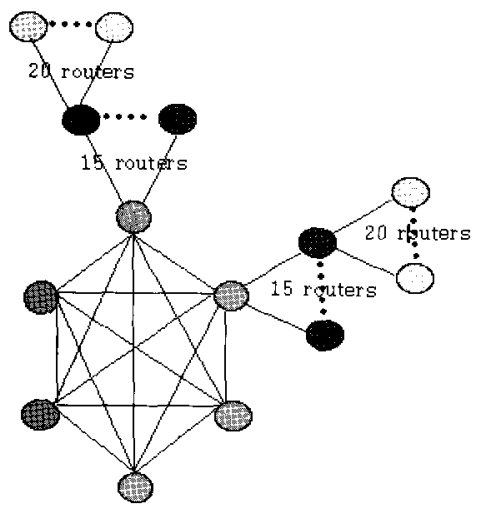

(그림 7) Transit-Stub 토폴로지

6개의 Transit Domain을 형성하고, 각 Transit Domain은 15 개의 라우터를 연결한다. 그리고, 90개의 Stub Domain은 각각 20 개의 라우터로 연결한다. 본 논문에서는 토폴로지상에 서 종단의 라우터를 하나의 물리적인 서브넷으로 간주한다. Core 영역은 대역폭 $20 \mathrm{Mb} / \mathrm{s}$, 전송 지연 $5 \mathrm{~ms}$, Transit Domain영역은 대역폭 $15 \mathrm{Mb} / \mathrm{s}$, 전송 지연 $10 \mathrm{~ms}$, Stub Domain 영역은 $10 \mathrm{Mb} / \mathrm{s}$, 전송 지연 $20 \mathrm{~ms}$ 라고 가정한다. 각 노드의 생성은 생성율 4.0 의 포아송 분포를 가정하였고, 생성 된 노드들이 멀티캐스트 그룹에 참가하는 시간은 노드가 생 성 된 이후 50 개의 노드들이 생성되는 단위 시간을 평균으로 하는 지수 분포를 따른다고 가정하였다. 그리고 생성된 노드 들의 요구 대역폭은 $0.5 \mathrm{Mb} / \mathrm{s}$ 에서 $2 \mathrm{Mb} / \mathrm{s}$ 까지 무작위로 할당
하였다. 이와 같이 할당된 요구 대역폭은 Best Fit에서 서브 넷 그룹을 선택하기 위한 기준이 된다. 이러한 토폴로지에서 Static과 QOS 기반 트리 방식의 성능을 측정하기 위해서, 초 기 지연, $\mathrm{SM}$ 상에서 메시지 복잡도, 부모 노드 선택 분포, 요 구 대역폭 사용율을 실험하였다.

위의 Transit-stub 토폴로지에서 하나의 미디어 전송 서버 와 1000 개의 수신 노드가 토폴로지에 연결될 경우에 초기 지 연을 측정하였다. 즉, 멀티캐스트 그룹에 참가하는 노드가 JR 메시지를 보내고 $\mathrm{SM}$ 으로부터 부모 노드를 지정 받은 다음, 미디어 스트림의 첫 프례임이 부모 노드에서 진입하려는 노 드에게 전송되기까지의 시간을 측정하였다. $\mathrm{QOS}$ 기반 트리 방식을 이용할 경우, $\mathrm{SM}$ 에서 후보 부모 노드의 수를 $5,10,30,50,100$ 개로 지정하면서 실험을 하였다.

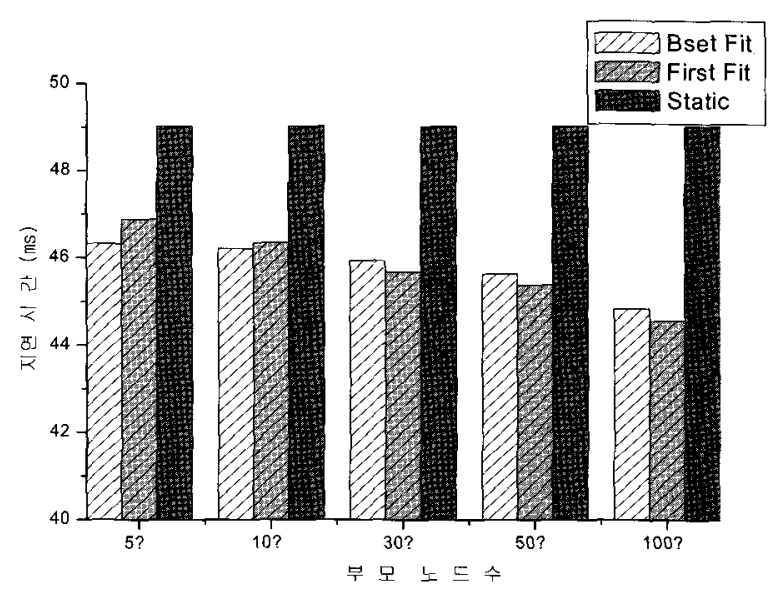

(그림 8) 초기 지연 시간 비교

실험 결과, (그림 8)에서 $\mathrm{Q} 0 \mathrm{~S}$ 기반 트리 방식의 초기 지연 시간이 Static Tree 방식보다 작았다. Static Tree 방식은 하 나의 부모 노드를 지정하는 반면에 QoS 기반 트리 방식은 여러 후보 부모 노드의 정보를 주고, 그 중 가까운 위치의 노 드를 부모 노드로 설정하기 때문에 초기 지연 시간이 작다. 즉 가까운 위치의 부모 노드를 선텍하는 방법은 복수 개의 부모 노드 후보 중에서 DMA의 정보 테이블에 있는 From'To $\mathrm{B} / \mathrm{W}$ 필드를 이용하여 링크 대역폭이 가장 큰 부모 노드를 선택하기 때문에 본 논문에서 제안하는 방식이 Tree 레벨에 따라서 부모 노드를 선택하는 Static Tree 방식보다 성능이 더 우수하다. Static Tree 방식은 서브넷 그룹의 깊이에 따라 하나의 서브넷 그룹을 지정함으로서 일정한 수치를 유지한다. 가까운 위치에 있는 부모 노드를 선택하는 개념은 물리적으 로 가까운 위치에 존재하는 것이 아니라 논리적으로 대역폭 의 대소에 따라서 가까운 위치를 의미하는 것이다.

$\mathrm{SM}$ 은 노드 진입 신청을 하는 $\mathrm{JR}$ 메시지와, 상태 보고를 하는 SR 메시지를 받는다. Static 및 $\mathrm{QOS}$ 기반 트리 방식을 이용하는 경우, SM에서 받는 메시지 량을 측정하여 메시지 복잡도를 알아보았다. 1 분마다 1000 개의 노드가 토폴로지 참 가 신청을 하고, 30 초마다 $\mathrm{SR}$ 메시지를 $\mathrm{SM}$ 에게 상태 정보 
메시지를 전송하였을 때, $\mathrm{SM}$ 에서 처리하는 메시지의 복잡도 를 기준으로 Static 및 Automatic Tree방식의 성능을 측정하 였다. 본 실험에서는 10 분 동안 총 10000 개의 노드를 멀티캐 스트 서비스에 참가시켰다.

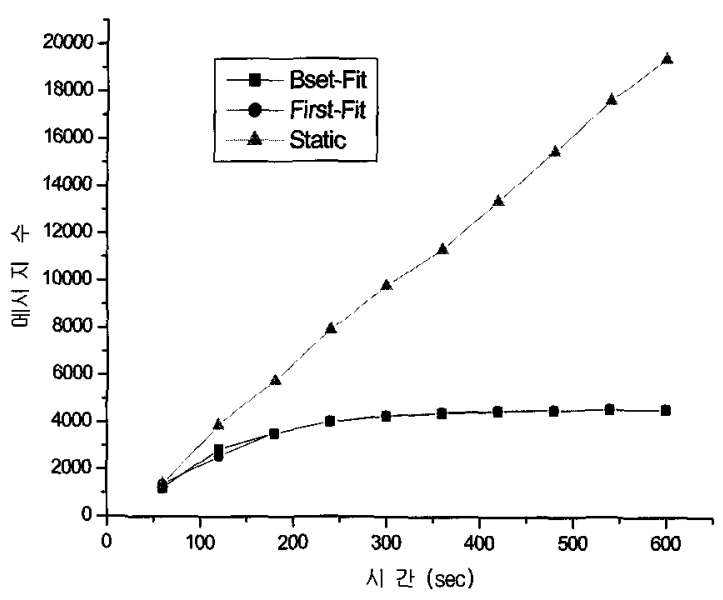

(그림 9) SM에서의 메시지 복잡도 비교

(그림 9)에서 Static Tree 방식이 시간에 따라 비례적으로 메시지 량이 늘어남을 알 수 있으며, QoS 기반 트리 방식은 Static Tree 방식이 비해서 메시지 처리량이 작음을 알 수 있 다. 이것은 $\mathrm{QOS}$ 기반 트리 방식이 DMA에서 분산적으로 메 시지를 처리함으로서 $\mathrm{SM}$ 의 메시지 처리량을 줄여 주기 때문 이다.

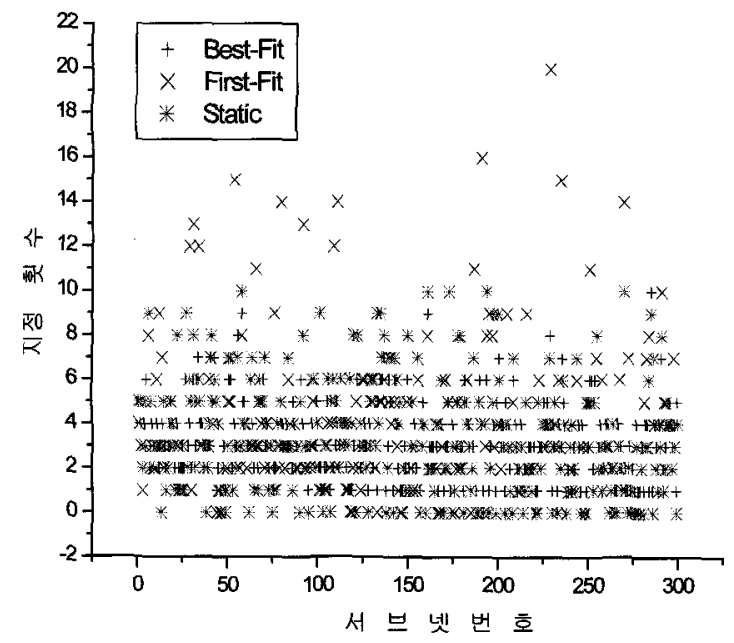

(그림 10) 서브넷 그룹 선택 분포도

융용 계층 멀티캐스트의 효율을 측정하는 요소 중 하나가 노드들의 분포이다. 본 논문에서는 노드들이 고정 $\mathrm{IP}$ 를 이용 한다고 가정함으로, 노드들의 유동 사항은 없다고 간주하였 다. 멀티캐스트 트리에 연결 요청을 할 때, 부모 노드들을 선 택하는데 있어서 부모 서브넷 그룹들이 균등하게 선택되었는 지를 측정하었다. 본 실험에서는 그래프의 복잡도를 줄이기
위해서 (그림 7)의 Transit-Stub 토폴로지를 축소하여 실험을 실시하였다. 즉, Transit Domain의 라우터를 5 개로 줄이고, Stub 도메인의 라우터를 10으로 줄여서 실험하였다. 그러므 로, 본 실험에서는 서브넷 그룹이 총 300 개가 있는 토폴로지 를 구성하였다. 그리고, 이러한 토폴로지에서 1000 개의 노드 가 멀티캐스트 서비스에 참가하였다. $\mathrm{X}$ 축은 선택되어진 부모 노드가 있는 서브넷 그룹의 번호를 나타내며, $\mathrm{Y}$ 축은 선택되 어진 횟수를 나타넨다.

(그림 10)과 같이 부모 서브넷 그릅 선택 분포도를 측정한 결과는 First-Fit이 산만하게 서브넷 그룹을 선택하고 있으며, Best-Fit과 Static Tree방식이 균등하게 부모 서브넷 그룹을 선택하였다. 특히 Static Tree 방식은 Tree의 깊이에 따라서 서브넷 그룹을 선택하기 때문에 가장 나은 성능을 보였지만 Best-Fit과는 무시할 정도의 작은 성능 차이를 보였다.

본 논문에서는 유비퀴터스 네트워크와 같은 환경에서 다양 한 조건의 단말들이 존재한다고 가정하고 각각의 노드들이 요구하는 대역폭의 만족도를 실험하였다. (그림 7)의 토폴로 지에서 50000 개의 노드를 멀티캐스트 서비스에 참가시키고 부모 노드로부터 할당된 대역폭과, 사용자가 요구하는 대역폭 의 관계를 이용하여 요구 대역폭 만족도를 측정하였다.

$$
\frac{\sum B^{R e q}}{\sum B^{\text {Alloc }}} \times 100
$$

(식 7)은 사용자 요구 대역폭 만족도를 나타내는 것으로 $B^{R e q}$ 는 사용자 요구 대역폭이고 $B^{A l l o c}$ 은 부모 노드로부터 실 제 할당 된 대역폭을 나타낸다.

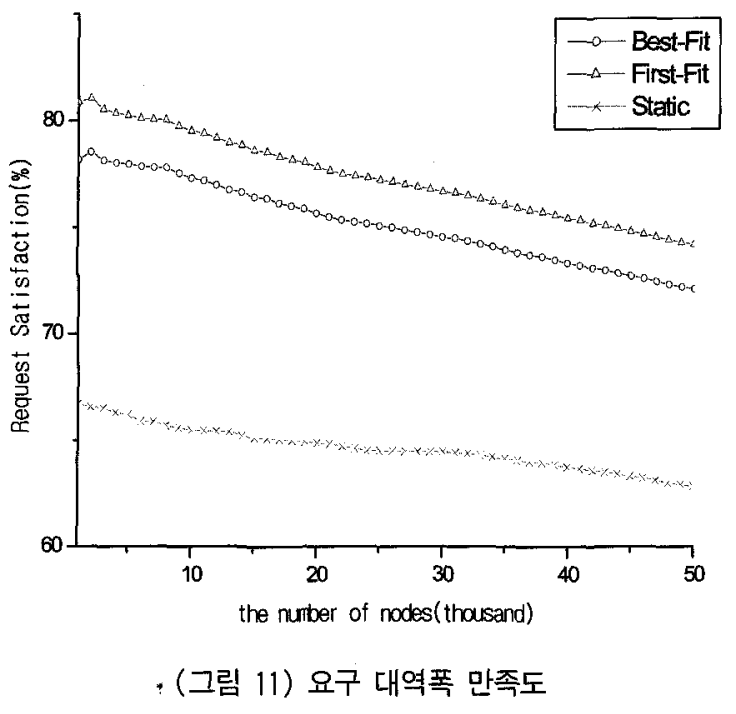

요구 대역폭 만족도 실험 결과 (그림 11)과 같은 결과가 나타났다. First-Fit이 가장 좋은 요구 대역폭 만족도를 보이 고 있고, First-Fit은 약 2-3\%정도 낮게 나타났으며 Static 
Tree 방식은 QoS를 전혀 고려하지 않기 때문에 가장 낮은 성능을 보인다. First-Fit이 Best-Fit보다 더 좋은 성능을 보 이는 이유는 항상 최대 대역폭을 가진 서브넷 그룹을 선택하 기 때문이다. 그러나 First-Fit과 Best-Fit의 차이는 거의 무 시할만한 수준이다.

\section{5. 결론 및 향후 연구 과제}

본 논문에서는 응용 계층 멀티캐스트를 위한 표준인 $\mathrm{RMCP}$ 기반의 응옹 계층 멀티캐스트에서 $\mathrm{QOS}$ 를 향상시키기 위한 기법들을 제안하였다. 기존의 RMCP 기법은 Static Tree 방식을 이용하기 때문에 멀티캐스트 트리의 레벨에 따 라서 하나의 부모 노드를 지정함으로 초기 지연이 발생하고, 사용자 요구 대역폭을 고려하지 않기 때문에 $\mathrm{QOS}$ 측면에서 비효율적이다. 그러나 본 논문에서는 이러한 문제점을 해결하 기 위해서 새로운 $\mathrm{QoS}$ 기반 트리 방식을 제안하였고 BestFit과 First-Fit을 이용함에 따라서 사용자 요구 대역폭을 개 선시켰다. Best-Fit은 사용자 요구 대역폭과 유사한 전송 대 역폭을 가지는 다수의 서브넷 그룹 중에서 가장 효율적인 서 브넷 그룹을 선택할 수 있는 방법을 졔공하고 First-Fit은 최 대 전송 대역폭을 가지는 서브넷 그룹을 이용하여 멀티캐스 트 트리를 구성할 수 있다. 특히 Best-Fit은 기존의 Static Tree 방식이나 First-Fit보다 초기 지연 및 메시지 복잡도 면 에서 더 효율적이다. 그리고 Best-Fit과 First-Fit은 사용자 요구 QOS를 만족시킬 수 있다.

향후에는 유비쿼터스 컴퓨텅 환경에서 효율적인 응용 계층 멀티캐스트 서비스를 제공하기 위해서 혼잡 제어에 대한 연 구를 실시하고, 단말의 이동성 및 서비스의 이동성을 지원하 는 응용 계층 멀터캐스트 기법을 연구할 것이다.

\section{참 고 문 헌}

[1] Seok Joo Koh, "Relayed Multicast Protocol-Framework", ITU-T Rec. X.603 | ISO/IEC 16512-1, November, 2005.

[2] Seok Joo Koh, "Relayed Multicast Protocol-Part 2 : Specification for simplex group applications", $2^{\text {nd }} \mathrm{CD}$ ballot of ITU-T X.603.1|ISO/IEC CD16512-2, Working ITU-T Q.1/17, March, 2005.

[3] Y.-h. Chu, S. G. Rao, and H.Zhang, "A Case for End System Multicast", ACM SIGMETRICS 2000, June, 2000.

[4] D. Pendarakis, S. Shi, D. Verma and M. Waldvogel, "ALMI :An Application Level Multicast Infrastructure", the 3rd Usenix Symposium on Internet technologies \& Systems (USITS 2001), March, 2001.

[5] L. Mathy, R. Canonico and D. Hutchison, "An verlay Tree building Control Protocol", NGC 2001, November, 2001.

[6] M. Kwon and S. Fahmy, "Topology Aware Overlay networks for Group Communication", Proceeding of NOSSDAV'02, May, 2002.

[7] M. Baa, H.Deshpande and H. Garcia-Molina, "Transience of Peers \& Streaming Media", HotNets-I, October, 2002.

[8] Beichuan Zhang, Sugih Jamin and Lixia Zhang, "Host Multicast: A Framework for Delivering Multicast to End Users", IEEE INFOCOM 2002, New York, US, June, 2002.

[9] Sylvia Ratnasamy, Mark Handley, Richard Karp, Scott Shenker, "Application-level Multicast using Content-Addressable Networks", Lecture Notes in Computer Science, 2001.

[10] S. Banerjee, B. Bhattacharjee, and C. Kommareddy. "Scalable application layer Multicast", Technical report, UMIACS TR-2002.

[11] J. Jannotti, D. K. Gifford, K. L. Johnson, M. F. Kaashoek, and J. W. O'Toole Jr. "Overcast: Reliable Multicasting with an overlay network" In Proceedings of the Fourth Symposium on Operating System Design and Implementation (OSDI), October, 2000.

[12] Y. Chawathe. "Scattercast: an architecture for internet broadcast distribution as an infrastructure service", In $\mathrm{PhD}$ Thesis, University of California at Berkeley, 2000.

[13] FRANCIS, P. "Yoid: Extending the internet Multicast architecture", Unpublished paper, available at http://www. aciri.org/yoid/docs/index.html, Apr., 2000.

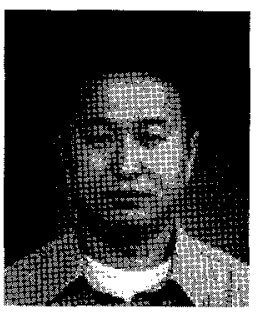

\section{박 시 용}

e-mail :sypark@melon.cs.pusan.ac.kr 1997년 경성대학교 전자계산학과(학사) 2001년 부산대학교 대학원 멀티미디어과 (이학석사)

2003년 부산대학교 대학원 전자계산학과 박사과정 수료

2005년 부산대학교 대학원 전자계산학과(이학박사)

관심분야: 멀티미디어, 모바일 네트워크, 인터넷 QoS, Overlay Multicast 


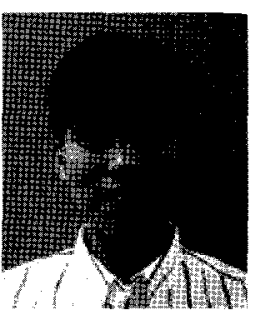

\section{김 성 민}

e-mail : morethannow@pusan.ac.kr 2001년 부산대학교 전자계산학과

2003년 부산대학교 전자계산학과(석사)

2003년 현재 부산대학교 컴퓨터공학과 박 사과정

관심분야: 트랜스코딩, 멀티미디어 스트리

밍, Overlay Multicast

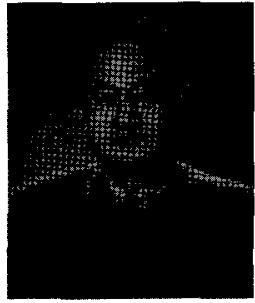

\section{정 기 동}

e-mail : kdchung@melon.cs.pusan.ac.kr 1973년 서울대학교 응용수학과(학사) 1975년 서울대학교 대학원 전자계산학과 (이학석사)

1986년 서울대학교 대학원 전자계산학과 (이학박사)

1990년 1991년 MIT대학 교환교수

1995년 1997년 부산대학교 전자계산소 소장

1999년 2001년 부산대학교 BK21단장

1978년 - 현재 부산대학교 전자계산학과 교수

관심분야: 멀티미디어, 모바일 네트워크, Overlay Multicast 